\title{
Fab Fragment
}

National Cancer Institute

\section{Source}

National Cancer Institute. Fab Fragment. NCI Thesaurus. Code C13246.

Part of an immunoglobulin antibody that binds a specific antigen and consists of both a light chain and part of a heavy chain. By comparison, natural antibodies consist of two heavy and two light chains. An FAB (fragment antibody) offers the advantages of smaller size and lower cross-reactivity compared to the complete antibody. ( $\mathrm{NCIO4)}$ 